\title{
The Paradigm Shift of College Career Counseling under the Complexity Background
}

\author{
Weixi Zeng, Lu Xu* \\ School of Public Affairs and Administration, University of Electronic Science and Technology of China, Chengdu, \\ Sichuan, China \\ *Corresponding author. Email: xulu0613@qq.com
}

\begin{abstract}
Along with the gradual awareness of the complexity of career development, research paradigm has changed significantly. At present, career counseling present these tendencies: (1) the complexity characteristics has been explained in the framework of career chaos theory; (2) individual's unique life experience, meaning construction, as well as the serendipity are given full attention; (3) the pursuit of career counseling is no longer rigid certainty and instead stresses the importance of continuously learning and adaptation to enhance "meta-competence";(4) information-giving, rational decision-making and narrative-oriented technology has been integrated.
\end{abstract}

Keywords: Career development, theory of chaos, career counselling

Under the background of the financial crisis, the employment problem of college students is getting more and more serious, which has attracted the attention of senior government officials. Many colleges and universities have taken it as a political task and launched the so-called "100-day breakthrough" in employment. Such "vocational guidance" activities focus on short-term effects and can solve the immediate problems, but most of them take temporary measures instead of permanent ones. To fully and accurately popularize and practice the concept of "career counseling" is the fundamental approach beneficial to individual's lifelong development. Career counseling is the upgrade of vocational guidance. Vocational guidance focuses on "how to find a job", while career counseling has a higher level, emphasizing "what kind of life to live". This article focuses on the thinking that career counseling in colleges and universities should change under the background of complexity, hoping to point out the new direction of career education for practical workers in college career counseling.

\section{FULLY UNDERSTAND THE COMPLEXITY NATURE OF CAREER DEVELOPMENT}

\subsection{Career Evolution Is Influenced by Multiple Factors}

Super put forward the archway model of career development in 1990, revealing that career development is influenced by multiple factors. In this archway mode, there are left and right supporting pillars: on the left is physiological pillar, mainly intelligence, sexual orientation, temperament, personality and other genetic related individual traits. On the right is the environmental pillar, mainly the growth background of individuals, including schools, families, peers, social, political and economic backgrounds, etc. The bottom is the foundation cast by the two pillars. The two pillars extend upward and gradually form an arch structure with individual self-concept as the core through different stages of career evolution. In addition, Patton and McMahon (1999) put forward a systematic framework for career development, which also shows that career development is influenced by many factors in the internal and external environment. These influencing factors recursively circulate and evolve in the time dimension, accompanied by many mutation factors, thus aggravating the complexity of development and making accurate prediction difficult (McMahon, 2008).

\subsection{Complexity of Self-Concept}

Career counseling attaches importance to the development of self-concept. Several theories of career counseling believe that individual career decision-making behavior is a realization of self-concept. Assisting individuals to acquire rational self-concept is an important goal of career counseling. "Self" is a complex cognitive object with self as process: from birth to death, the objective connotation of self is constantly changing and is a process of becoming. It is also a self as concept and as it is being. The concept of professional self-advocated by Holland and the theory of idiosyncratic factors is basically static, focusing on the first career choice, and there seems to be an adaptation once and for all. Savichas (2002) believed that Super no longer regarded career as a process of "unfold" afterwards, but as a process of "constructed". 
Kelly (1955)'s personal construction theory held that everyone is a scientist of life [4]. Career decision is life experiment, which is a process of collecting data, verifying patterns and modifying parameters. Life experiments may have leading hypotheses, schema or personal theory, and the hypotheses may also be derived from previous experimental results. A steady stream of life experiments give feedback to individuals about their own internal and external environment, which individuals form career belief and life philosophy based on. Subsequent life experiments may strengthen and perfect the existing belief system to make it fine, complicated and stable, or overthrow and reconstruct the existing system due to them. In short, the formation of life theory is a personal history of clinical work.

Life experiments shape personal construction, which in turn guides the direction of experiments. It is an orderly organization with considerable, repairable and modifiable construction. Various departments within the organization are interrelated and respond to the environment. If we can understand the operation mode of this organization, we can predict, expect or judge our own behavior more clearly.

\subsection{Non-linear Characteristics of Career Development}

Super directly talked about the process of career development and believed that it goes through a series circle of life stages such as growth, exploration, establishment, maintenance and decline, and each stage has a small cycle. The transition period is often affected by various unstable factors, which will bring about a process of re-exploration and re-establishment, thus forming a unique individual career form. Career development is not following a simple, direct and logical path. It has nonlinear characteristics. Mitchell(1999) and others discussed the impact of uncertain events on career choice; Morowitz (2002) found that the career development of a group of individuals with the same Holland career type diverged after a period of time, and this change cannot be predicted by the original Holland type description; Pryor(2003) and others found that $70 \%$ of a large sample of college students reported that their career development was greatly affected by unexpected events, including unexpected meetings, diseases and spiritual enlightenment; Bloch(2005) explicitly introduced the concept of complexity science into career development, pointing out that career development is a self-organizing adaptation process; Bright(2005) pointed out that chaos theory can better describe professional behavior and is of great application value to career counseling; Duffy(2000) pointed out in particular that chaos theory has a better curative effect when it is used to coach employees in career plateau period. The theory of career chaos integrates the above related researches and explains the dynamic evolution and nonlinear structural characteristics of career development with the concept of complexity science.
Specifically, career development has the following characteristics: (1) Self-generation and self-regeneration. Career development is characterized by active adaptation, and everyone can shape his career course according to his own script to a certain extent. (2) Open dynamic system. As an adaptive entity, individuals are always engaged in open exchange and network participation with the internal and external environment. The deeper the involvement, the stronger the plasticity. (3) Sensitive dependence. The small difference of initial state will lead to great variation if it is continuously iterated. Seemingly insignificant events often have unpredictable impacts on the career development of the parties concerned. (4) There is no ultimate steady state. Everyone is looking for a phased steady state, but the steady state is temporary, phase shift occurs at any time, and it is necessary to keep the role self-flexible due to the "time-position" change. (5) Attractor is everywhere. There are two kinds of attractors, one kind is similar to "fixed number", such as fixed-point attractor, pendulum attractor and ring attractor, which make the self-adaptive entity maintain a convergent steady state under its action. Holland's professional personality type is this kind of attractor. The other is strange attractor, which is the reaction of "fixed number" and the driver of sudden changes, such as unexpected events. (6) Fractal characteristics. Fractal is a self-similar structure, in which small cycles are nested in the big cycle of career development, and there is some orderliness and similarity in the periodic transformation of large and small cycles. (7) Only by improving the spirituality of one's career can he/she respond to all changes with the same. Career development will undergo complex phase changes. If one can improve his/her spirituality and find native place of mind, one can keep shape dispersing but spirit concentrating and actively cope with the discomfort of changes.

\section{Paradigm Shift for Career Counseling}

\subsection{Do not Aim at Rigid Pursuit of Certainty}

Traditional idiosyncratic factor theory emphasizes "pure causal reasoning" as the basis of "person-job matching", which may cause that current career counseling is still recognized to a large extent as a process to reduce uncertainty in career decision-making. Visitors turn to consultants because of career selection difficulties. The first reaction of many consultants is to let the visitors do a series of psychological tests. The test report can provide some clear matching information for the visitors, which can reduce confusion and increase certainty to a certain extent. Career counselors have a tendency to prefer visitors who follow their own direction, and those who have not been able to make decisions for a long time after completing the tests are often regarded as "indecisive". Some career counselors even think that such indecisive visitors should turn to counselors who are specialized in 
solving deep psychological problems, and they seem to be helpless to such visitors (Mitchell, 1999). This "fast positioning" consulting tendency has its cultural roots: if a person can make a clear decision, he will be regarded as a confident and responsible person, while a person who does not have a clear idea is regarded as insipid and unreliable, which is typical in American culture.

However, if career development follows a simple, direct and logical path, only rational planning and simple matching can meet the needs of consultation. Unfortunately, today's world of work is different from the past due to great technological changes, with the emergence of boundaryless career (Arthur, 1994). In fact, job descriptions are constantly changing in all work departments. Some occupations are becoming obsolete and disappearing, while unforeseen occupations are being created. Although one of the main goals of career counseling is to help visitors understand its future development direction, it will become increasingly difficult for career counselors to continue to effectively achieve this goal according to the traditional counseling mode.

Faced with uncertainty, consultants should portray themselves as promoters and guides of career development, rather than as matchmakers between "visitors" and "good jobs" (Krumboltz, 2004). Visitors might have irrational demands for consultants, such as asking for definite options. However, consultants should not be forced to cater to and comply with such needs, but should correct and clarify such irrational beliefs and help visitors to acquire a "positive sense of uncertainty" (Gelat, 1989), that is, to accept the inevitable uncertainties, information, emotion, cognitive judgment and probability of success, in making decisions with a positive and optimistic attitude and to enhance visitor's ability to tolerate ambiguity.

\subsection{Career Counseling Aims at Promoting Continuous Learning and Adaptation}

Krumboltz(1996) especially emphasized that the goal of career counseling is to improve the learning of new technologies, new concepts and new lifestyles. He believed that the phenomenon of career hesitation is mainly due to the lack of career-related learning experience or the lack of systematic career decision-making methods. Therefore, consultants should expand the new learning experience of their clients, encourage them to participate in various career exploration activities, actively create opportunities and benefit from them.

Visitors learn from psychological tests that there are many professions in society, some of which are unfamiliar to them and will also attract their interest in exploration. The consultant's training and accomplishments determine whether he is willing to have in-depth dialogue and exploration with the visitors on the test results, rather than making arbitrary decisions for the visitors. The result of the test is not for the purpose of decision but leading to subsequent exploration. Consultants should analyze with visitors why such test results appear? Is there any prejudice against other results? Whether there is an inappropriate self-restriction on oneself ... It is of great value to let visitors actively participate in the discussion of various potential possibilities. It can free visitors from self-restriction, expand self-boundary and broaden the space for career exploration.

Mitchell(1999) and Krumboltz and other scholars put forward the planned happenstance theory. This theory can be regarded as an extension of social learning theory. The main point of view is that the environment in which people grow up is full of numerous serendipities, which, whether positive or negative, provide unexpected learning opportunities. Counselors should let clients understand that luck is not occasional, and fortuity is a gift and chance, and it should be used well (Krumboltz,2004). We should take positive actions to create favorable conditions.

\section{TO CULTIVATE "META-COMPETENCIES" OF CAREER CONTINGENCY}

In the era of border-less career, technological progress will narrow individual differences, professional skills will be relatively devalued, the mobility of employees among different positions, professions, roles and organizations will be reduced, and career transition will become normal. Worker's meta-competencies to adapt to changes, such as interpersonal communication and learning ability, is extremely important. It helps individuals acquire, maintain and utilize certain qualifications to cope with the changing labor market (Van der Heijden,2002). Career development is complex and changeable, and meta-competencies is the core competitiveness of "constant response to changes". Under its guidance, individuals learn new knowledge and skills continuously, generate new decisions, and adapt to changes for ever. From this point of view, the goal of career counseling is not to know the individual's career type through psychological tests, but to arouse the individual's contingency awareness, improve and enhance their "meta-competencies". The concepts similar to "meta-competencies" include employability, career adaptability, and career spirituality. Scholars have the following views on its internal structure.

Mitchell(1999) believed that curiosity, perseverance, flexibility, optimism and adventure are five mental qualities that enable individuals to actively create, identify and benefit from opportunities. "Meta-competencies" of career adaptation can be called "career spirituality". It is at the highest level of "body, heart and soul", guiding career direction, identifies career information, assisting career decision-making and explaining career value, and is the soul of career development. Career spirituality can be divided into five dimensions, of which "meaning pursuit" is the core, "openness and flexibility" and "practical actions" are the knowing and doing guarantee and the "left wing", "optimistic and open-minded" and "tenacious and 
persistent" are the affection guarantee and the "right wing". Only when the core is correct, and the two wings are firm can one's career development soar. The goal of career counseling is to "correct the core" and "strengthen the two wings".

Fugate (2004) believed that "employability" is a psycho-social construct embedded in personal characteristics, including four dimensions: career identification, personal adaptability, social capital and psychological capital. Career identification refers to the individual's career self-knowledge system, including career goals, personality traits, values and career cognition. Personal adaptability refers to the willingness and ability to change personal accomplishment and adjust behavior to meet environmental needs, including optimism, willingness to learn, acceptance of changes, and internal control characteristics. Social capital refers to the social network owned by individuals, which can be used to expand personal identity and grasp career opportunities. Psychological capital refers to psychological background variables that affect personal career development, such as educational experience, work experience, self-efficacy, etc. Hall (2004) believed that "adaptability" and "self-consciousness" are the two main "mate-competencies" of career success and put forward a four-grid table of "adaptability-self-consciousness", which actually divides career adaptation into four forms. "Adaptability" is the quality of coping with sudden influences in career development. Self-awareness is the cognitive level of individuals to their own psychological quality. Kuijpers(2006) and other scholars believed that career meta-competencies have six dimensions: goal realization ability, process reflection ability, motivation reflection ability, job exploration ability, career control ability and networking ability.

\section{INTEGRATION OF CAREER COUNSELING METHODS}

Career counseling started from the three basic steps revealed by Parsons has urged the development of the theory of idiosyncratic factors, which is basically based on scientific reasoning. The philosophy behind it is that there is absolute truth in the universe and there is a linear causality between things. The rise of postmodernism, the combination of social constructivism and career counseling, has introduced non-linear and non-causal assumptions: there is no absolute truth and fact in the world, truth and fact come from the co-construction of human communities, thus establishing a consultation process of "deconstructing-reconstructing" the existing knowledge system of the parties.

Career counseling service can be divided into six levels: information provision, self-help exploration, workshops, career planning courses, group career counseling, individual career counseling, involving career information, decision-making skills and career beliefs. Career classification ceremony, information interview, on-the-spot visit, computer-aided career guidance system, and career psychological test are important sources of career information for individuals. Factor deletion method, grid technology and balance sheet technology are important skills for rational decision-making. Considering the complexity of career development, several new career counseling orientations have emerged in recent years, including the application of Jung's concept of simultaneity (Guindon, Hanna, 2002), planned happenstance theory (Mitchell, 1999), spirituality and career counseling (Bloch,1998), and narrative-oriented career counseling. These new counseling methods deal with the career perplexities encountered by visitors through career combination cards, paintings, tests, anecdotes, lifelines, life epics, career genealogy, role models, mythical metaphors, prototype analysis, retrospective reasoning, etc. They are committed to clarifying career values, resolving irrational career beliefs and understanding the meaning of life (McKay,2005).

\section{SUMMARY AND SUGGESTIONS}

Career counseling is a complicated system engineering. We can regard the contents of career counseling as a continuous spectrum of tasks. One end is to "find a definite job" and the other end is to "lead a spiritual life". During this period, the tasks that visitors and consultants need to face include a series of problems such as individual self-cognition, career cognition, career choice and decision-making, career adjustment, career transition, work-life balance, and pursuit of life meaning. It can be seen that career counseling topics are quite diverse, and this diversity itself reflects the complexity of career development. The traditional career guidance lacks sufficient understanding of the complexity of career development, overemphasizes the mechanical matching between individual quality and career type, and aims at eliminating uncertainty. The guidance method is relatively simple, mainly based on psychological evaluation to give individual career selection suggestions. Consultants play the role of matchmaker between visitors and careers. With the continuous development of career counseling practice, the complexity of career development has been clearly recognized. The theory of career chaos summarizes some typical complexity characteristics, such as sensitive dependence, fractal, attractor, etc. Under this background, the concept of career counseling has changed. The goal of career counseling is no longer to rigidly pursue the sense of certainty, but to pay more attention to the excavation and cultivation of the individual's continuous learning and adaptability in the process of career development, "teaching people to fish" instead of "giving people fish". Non-determinism paradigm has also emerged in counseling methods, such as career narrative, career genealogy, prototype analysis, etc. More emphasis is placed on personalized career interpretation and understanding rather than prediction and decision. Of course, career guidance under the background of complexity is not totally exclusive of the career guidance 
mode under the guidance of determinism. Because of the characteristics of changes in stages of individual's career development, different consultation modes are applicable to each stage, and there is no single general consultation mode. For practitioners of career counseling, they should fully understand the complexity of career development, sort out the counseling tasks they may face and master all kinds of counseling methods. Under the guidance of the relevant theoretical framework, they should simplify and organize the complex problems, accurately diagnose and suit the remedy to the case, fix the medicine to the disease, and improve the level of career counseling as a whole.

\section{REFERENCES}

[1] Patton, W., McMahon, M. Career development and systems theory: A new relationship. Pacific Grove, CA: Brooks/Cole, 1999.

[2] McMahon, M.L., Watson, M.B. Systemic Influences on Career Development: Assisting Clients to Tell Their Career Stories. The Career Development Quarterly, 2008, 56(3), 280-288.

[3] Savickas, M.L. Career construction: A development theory of vocational behavior. In D.Brown and Associates (Eds), Career choice and development (4th Ed.).San Francisco, Calif: Jossey-Bass Publishers, 2002.

[4] Kelly, G.A. (1955). The psychology of personal construct. New York: Norton.

[5] Mitchell, K.E., Levin, A.S., Krumboltz, J.D. Planned happenstance: Constructing unexpected career opportunities. Journal of Counseling and Development, 1999, 77(2), 115-124.

[6] Morowitz, H. J. The emergence of everything: How the world became complex. New York: Oxford University Press, 2002.

[7] Pryor, R. G. L., Bright, E. H. Order and chaos: A twenty-first century formulation of careers. Australian Journal of Psychology, 2003, 55(2), 121-128.

[8] Bloch, D. P. Complexity, chaos, and nonlinear dynamics: A new perspective on career development theory. The Career Development Quarterly, 2005, 53(3), 194-207.

[9] Bright, J. E. H., Pryor, R. G. L. The chaos theory of careers: A user's guide. The Career Development Quarterly, 2005, 53(4), 291-305.
[10] Duffy, J. A. The application of chaos theory to the career-plateaued worker. Journal of Employment Counseling, 2000, 37, 229-237.

[11] Arthur, M.B. The boundaryless career: A new perspective for organizational inquiry. Journal of organizational Behavior, 1994, 15, 295-306.

[12] Krumboltz, J. D., Levin, A. Luck is no accident: Making the most of happenstance in your life and career. Atascadero, CA: Impact, 2004.

[13] Gelatt, H.B. Positive uncertainty: A new decision-making framework for counseling. Journal of Counseling Psychology, 1989, 36, 252-256.

[14] Van der Heijden, Beatrice I.J.M. Prerequisites to guarantee life-long employability. Personnel Review, 2002, 31(1), 44-61.

[15] Fugate, Mel, et al. Employability: a psycho-social construct, its dimensions, and application. Journal of Vocational Behavior, 2004, 65(1), 14-38.

[16] Hall, Douglas T. The protean career: A quarter-century journey. JBehavior, 2004, 65, 1-13.

[17] Kuijpers, M., Schyns, B., Scheerens, J. (2006). Career Competencies for Career Success. The Career Development Quarterly, 55(2), 168-178.

[18] McKay, H., Bright, J.E.H., Pryor, R. G. L. Finding order and direction from chaos: a comparison of chaos career counseling and trait matching counseling. Journal of Employment Counseling, 2005, 42(3), 98-112. 